We are indebted to the nursing staff of the Royal Victoria Infirmary and Rye Hill Hospital for the prompt resuscitation of these patients; to several colleagues, including Dr. P. R. Uldall and Dr. R. W. Elliott, for help in their management; to Professor D. N. Walder and Dr. D. A. Shaw for expert advice; and to the technical staff of the renal unit for suggestions on the design of air embolism monitors.

\section{References}

Anderson, R. M., Fritz, J. M., and O'Hare, J. E. (1965). Fournal of Thoracic and Cardiovascular Surgery, 49, 440

Berlyne, G. M., Lee, H. A., and Rose, C. H. (1968). Lancet, 1, 184

Cockett, A. T. K., Makamura, R. M., and Franks, J. J. (1965). Surgery, 58, 384.
Cohen, S., Lidsky, I., Kest, L., Kastagir, B., and Vertes, V. (1968). Transactions. American Society for Artificial Internal Organs, 14, 421.

Emery, E. R. J. (1962). Anaesthesia, 17, 455.

Emery, E. R. J. (1962). Anaesthesia, 17, 455.

Hartveit, F., Lystad, H., and Aminken, A. (1968). British fournal of Experimental Pathology, $49,81$.
.

Michenfelder, J. D., Martin, J. T., Altenburg, B. M., and Rehder, K. (1969). Fournal of the American Medical Association, 208, 1354.

Musgrove, J. E., and Macquigg, R. E. (1952). Fournal of the American Medical Association, 150, 28.

Nicks, R. (1969). Australian and New Zealand fournal of Surgery, 38, 328.

Richardson, B. W. (1866). Medical Times and Gazette, p. 110.

Richardson, H. F., Coles, B. C., and Hall, G. E. (1937). Canadian Medical, Association fournal, 36, 584 .

Severinghaus, J. W., and Stupfel, M. (1957). fournal of Applied Physiology, 10,335 .

Shaldon, S.. and McKay, S. (1968). British Medical fournal, 4, 671.

Verberckmoes, R., et al. (1967). Procedings of the European Dialysis and Transplant Association, 4, 73.

Workman, R. D. (1968). Aerospace Medicine, 39, 1076.

\title{
Passive Flexion and Femoral Vein Flow: A Study Using a Motorized Foot Mover
}

\author{
V. C. ROBERTS, S. SABRI, M. C. PIETRONI, V. GUREWICH, L. T. COTTON
}

British Medical fournal, 1971, 3, 78-81

\section{Summary}

The effect of rhythmic passive flexion of the foot on femoral vein blood volume flow rate has been investigated in 11 patients undergoing surgery for varicose veins. With rates of flexion varying from 24 to 50 per minute and with amplitudes varying from $20^{\circ}$ to $50^{\circ}$ it has been shown that the peak femoral vein flow can be increased to twice its normal value and that its pulsatility can be increased elevenfold. These increases are proportional to both the rate and the amplitude of the flexion, the maximum occurring, theoretically, when the foot is flexed $\pm 28^{\circ}$ about a line perpendicular to the leg.

The investigation has further shown that the effects of sustained passive flexion are maintained, without appreciable dimunition, for $\mathbf{3 0}$ minutes and that the maximum increases are produced in those patients who have the lowest resting flows. It is suggested that per-operative passive flexion of the feet may be a good prophylactic against postoperative deep vein thrombosis.

\section{Introduction}

Despite the impressive advances which are continually being made, postoperative deep vein thrombosis and its consequences remain a major hazard of modern surgery. Most venous thrombi originate in the deep veins of the calf, especially those draining the soleus muscle (Gibbs, 1957; Roberts, 1963; Cotton and Clark, 1965). Dilatation of the soleal sinuses, with advancing age and progressive rises in body weight, increases the pooling of venous blood within them (Gibbs, 1957), a

\footnotetext{
Department of Biomedical Engineering, King's College Hospital Medical School, London S.E.5

V. C. ROBERTS, M.SC., PH.D., Honorary Lecturer in Biomedical Engineering S. SABRI, PH.D., Honorary Senior Surgical Registrar/Lecturer

M. C. PIETRONI, F.R.C.S., Surgical Registrar

V. GUREWICH, M.D. (present address: Central Park West, New York) L. T. COTTON, M.CH., F.R.c.s., Surgeon and Director
}

condition which is further aggravated by anaesthesia and the associated inactivity of the calf muscles (Cotton and Clark, 1965).

It has been shown that the foot-to-groin transit times of superficial venous flow in patients who were ambulant postoperatively were considerably less than in those who were confined to bed (Wright, Osborn, and Edmonds, 1951), but that they could be halved by active exercise of the foot (Wright and Osborn, 1952; Cotton, Fowler, and Miles, 1959). Thus it was felt that active exercise of the calf muscles during the postoperative period, together with early ambulation, might help to prevent stasis of blood in the soleal sinuses. It has recently been suggested, however, that most postoperative deep vein thrombi originate during operation (Flanc, Kakkar, and Clarke, 1968; Negus, Pinto, LeQuesne, Brown, and Chapman, 1968) or shortly afterwards (Sabri, Roberts, and Cotton, 1971). Thus it would seem essential that the exercise of the calf muscles should start at operation and continue into the immediate postoperative period.

Per-operative exercise of the calf muscles was first reported by Doran, Drury, and Sivyer (1964). They showed, using ${ }^{24} \mathrm{NaCl}$; that the foot-to-groin transit time reached its highest level during operation, but that it could be reduced by electrically stimulating the calf. This work was subsequently followed by clinical trials which showed that per-operative calf stimulation reduces the incidence of postoperative deep vein thrombosis (Doran and White, 1967; Browse and Negus, 1970). Other workers, however, have failed to prove conclusively the efficacy of electrical stimulation as a prophylactic against deep vein thrombosis (DeJode, Khurshid, and Walther, 1970; Moloney, Morrell, and Fell, 1970). This suggested that the effects of calf exercise on blood flow warranted further investigation.

Critical assessment of the effects on vessel blood flow of electrical stimulation of the calf is difficult for several reasons. Precise control of the site and intensity of the stimulus, and thus the muscle contraction, is very difficult. Furthermore, the measurement of instantaneous flow changes are difficult to make. With an electromagnetic flowmeter, for example, gross electrical interference from the stimulating signal prevents measurements from being made during the stimulation period. Passive flexion of the foot on the other hand has several advantages: firstly, it mimics active calf contraction by producing compression of the calf veins; secondly, the flexion can be 
precisely controlled in terms of rate and amplitude; thirdly, it will not produce electrical interference, thus making electromagnetic flow measurements possible; and finally, its effects should not be markedly dependent on the anaesthetic condition of the subject.

The purpose of this paper is to report the effects on femoral vein blood flow of rhythmic passive flexion of the feet.

\section{Patients and Method}

Eleven patients undergoing surgery for bilateral varicose veins were asked for their informed consent to the procedure, which was fully explained in every case. Blood flows were measured with a Nycotron 372 electromagnetic flowmeter and Nycotron cuff flow probes type PS, and a standard procedure reported previously (Spiro, Roberts, and Richards, 1970).

The machine used to produce the controlled passive flexion of the foot (foot mover) is shown in Fig. 1. It is intended for use on supine subjects, whether conscious or unconscious, and can be clamped to any operating table or bed as required. It consists essentially of a foot board which is pivoted in the region of ten ankle. The feet are held in contact with the board, controlled oscillation of which is produced by an electrically driven crank mechanism. Fig. 2 shows a diagrammatic representation of the foot mover. By suitable adjustment of the crank mechanism, the foot can be flexed through an angle of $\theta^{\circ}$ about the vertical. The investigation was divided into three parts:

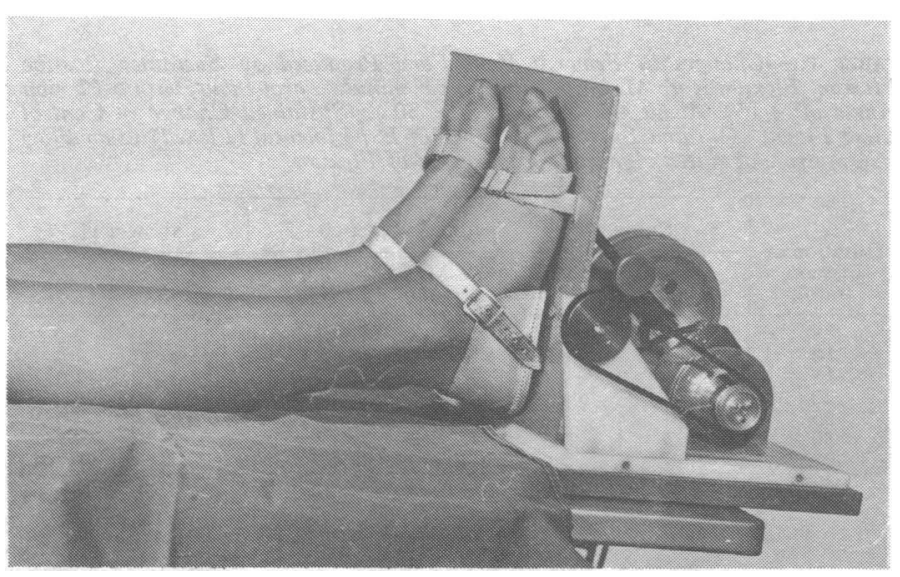

FIG. 1-Motorized foot mover for producing passive flexion of the calf muscle.

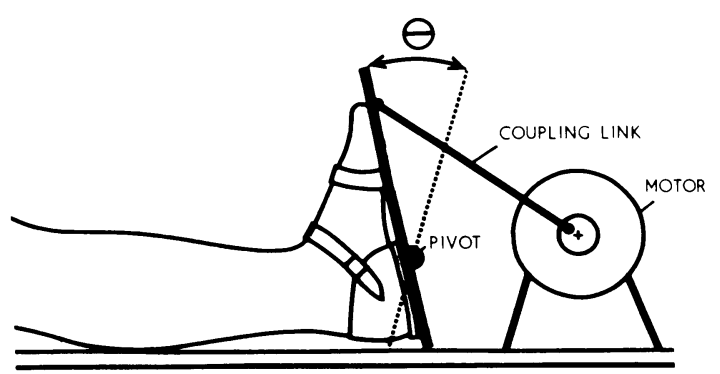

FIG. 2-Angulation of the foot over which control may be exercised by varying the length of the connecting rod and the throw of the crank.

(1) The effects of passive exercise of the calf muscle pump on venous flows was investigated in five patients. In each case one foot was flexed by the foot mover, while the other acted as a control. The foot was flexed at a fixed amplitude of $\Theta=30^{\circ}$-that is, the foot was flexed $\pm 15^{\circ}$ about the vertical. In each case a two-minute rest period with the foot extended was followed by a two-minute period of controlled flexion. Five different rates of flexion were studied, varying from 24 to 50 per minute.

(2) The effects of various degrees of flexion on venous flows were studied in a further series of three patients. As before, one foot was flexed while the other acted as a control. Similarly, a twominute rest period was followed by a two-minute period of controlled flexion. The rate of flexion remained constant at 50 per minute, while the amplitude of the flexion was varied in four steps, $\pm 10^{\circ}, \pm 15^{\circ}, \pm 20^{\circ}$, and $\pm 25^{\circ}$ about the vertical. The upper limit of these excursions having been previously determined as being within the limit of comfort for conscious subjects.

(3) The effects of continuous passive flexion on femoral vein flow were studied in the final series of three patients. Again, one foot was flexed while the other acted as control. The rate of flexion was 50 per minute, with an amplitude of $\pm 15^{\circ}$ about the vertical. The flexion was maintained for 30 minutes, and readings of flow were taken from the flow tracings at five-minute intervals. In order to avoid prolonging the operating time the effects of sustained flexion for longer periods was not investigated.

\section{Results}

Passive Flexion of Fixed Amplitude and Varying Rate.-The results of this part of the investigation are shown in Table I. The oscillation period ( $T$ ), which is the reciprocal of the rate of flexion, is tabulated against the sustained changes in flow produced in the control $\left(\Delta \mathrm{Q}_{\mathrm{c}}\right)$ and flexed $\left(\Delta \mathrm{Q}_{\mathrm{e}}\right)$ limbs. Also given are the changes produced in the peak venous flow in the flexed leg $\left(\Delta Q_{\max }\right)$ and the change in the amplitude of the pulsatile component of the flow wave in the same leg ( $\Delta$ Amp). The results from Table $I$ are plotted in Figs. 3 and 4. In Fig. 3 the mean percentage change in femoral vein flow at each of the five rates of flexion is plotted against the period of oscillation of the foot. The vertical and horizontal bars indicate \pm 1 S.D. about the mean value. The results show that as the period of oscillation decreases-that is, the rate of flexion increases-the change in flow in the flexed limb rises to a maximum of about $35 \%$. On the other hand, the flow changes produced in the control limb (about $5 \%$ ) is substantially independent of the period of oscillation. Fig. 4 shows the percentage change in the amplitude of the pulsatile component of the venous flow wave. As can be seen, the increase in pulsatility produced by passive flexion is about fourfold. Greater increases are produced as the rate of flexion increases.

TABLE I-Changes in Femoral Vein Flow Produced by Passive Flexion of Foot. Flexion Angle Maintained at $\left.\pm 15^{\circ}\right)$ about the Vertical. Oscillation Period $(T)$ Tabulated against Sustained Changes in Control Limb Flow $\left(\Delta Q_{c}\right)$ and in Experimental (Flexed) Limb Flow $\left(\Delta Q_{\mathrm{e}}\right)$. Change in Peak Vein Flow in Experimental Limb $\left(\Delta Q_{\max }\right)$ and Change in Amplitude of Pulsatile Component Experimental Limb $\left(\Delta Q_{\max }\right)$ and Chan
of Flow Wave $(\Delta A m p)$ are also Given.

\begin{tabular}{|c|c|c|c|c|c|}
\hline Subject & $\begin{array}{c}\mathrm{T} \\
(\mathrm{sec})\end{array}$ & $\begin{array}{l}\Delta Q_{c} \\
(\%)\end{array}$ & $\begin{array}{l}\Delta Q_{\mathrm{e}} \\
(\%)\end{array}$ & $\Delta \underset{(\%)}{Q_{\max }}$ & $\begin{array}{l}\Delta \mathrm{Amp} \\
(\%)\end{array}$ \\
\hline 1 & $\begin{array}{l}2 \cdot 22 \\
2.06 \\
1.71 \\
1 \cdot 48 \\
1 \cdot 34\end{array}$ & $\begin{array}{r}13 \cdot 2 \\
8 \cdot 7 \\
16 \cdot 0 \\
-1 \cdot 8 \\
7 \cdot 1 \\
\end{array}$ & $\begin{array}{r}0.0 \\
12.5 \\
2 \cdot 3 \\
22.4 \\
20 \cdot 4 \\
\end{array}$ & $\begin{array}{r}8 \cdot 3 \\
23 \cdot 8 \\
22 \cdot 7 \\
48 \cdot 8 \\
20 \cdot 4\end{array}$ & $\begin{array}{l}300 \\
250 \\
700 \\
387 \\
227\end{array}$ \\
\hline 2 & $\begin{array}{l}2.10 \\
1.80 \\
1.57 \\
1.48 \\
1.21\end{array}$ & $\begin{array}{r}4 \cdot 6 \\
12.9 \\
11.3 \\
-3.9 \\
6 \cdot 1\end{array}$ & $\begin{array}{r}7 \cdot 8 \\
35 \cdot 5 \\
28 \cdot 2 \\
27 \cdot 2 \\
62 \cdot 9\end{array}$ & $\begin{array}{l}10 \cdot 0 \\
32 \cdot 3 \\
31 \cdot 8 \\
40 \cdot 0 \\
51 \cdot 7\end{array}$ & $\begin{array}{r}133 \\
75 \\
31 \\
200 \\
1000\end{array}$ \\
\hline 3 & $\begin{array}{l}1.92 \\
1.72 \\
1.63 \\
1.37 \\
1.17\end{array}$ & $\begin{array}{r}0.0 \\
0.0 \\
12.5 \\
2.4 \\
6.7 \\
\end{array}$ & $\begin{array}{r}28.4 \\
-10.0 \\
38.0 \\
16.9 \\
19.4\end{array}$ & $\begin{array}{l}75 \cdot 0 \\
43 \cdot 4 \\
62 \cdot 8 \\
50 \cdot 0 \\
33 \cdot 3\end{array}$ & $\begin{array}{r}340 \\
256 \\
90 \\
183 \\
71\end{array}$ \\
\hline 4 & $\begin{array}{l}2.08 \\
2.02 \\
1.57 \\
1.38 \\
1.20\end{array}$ & $\begin{array}{r}5 \cdot 7 \\
7.4 \\
1.2 \\
10 \cdot 7 \\
2 \cdot 4 \\
\end{array}$ & $\begin{array}{l}39 \cdot 4 \\
37.0 \\
29 \cdot 3 \\
48 \cdot 8 \\
34 \cdot 5\end{array}$ & $\begin{array}{l}16 \cdot 5 \\
30 \cdot 0 \\
26 \cdot 7 \\
26 \cdot 7 \\
30 \cdot 0\end{array}$ & $\begin{array}{l}43 \\
61 \\
50 \\
48 \\
44 \\
\end{array}$ \\
\hline 5 & $\begin{array}{l}2.08 \\
1.83 \\
1.60 \\
1.41 \\
1.21\end{array}$ & $\begin{array}{r}-7 \cdot 5 \\
0.0 \\
0.0 \\
2 \cdot 1 \\
4.3\end{array}$ & $\begin{array}{l}40 \cdot 0 \\
37 \cdot 0 \\
30 \cdot 6 \\
37 \cdot 3 \\
40 \cdot 4\end{array}$ & $\begin{array}{l}104 \cdot 2 \\
104 \cdot 0 \\
107 \cdot 8 \\
116 \cdot 3 \\
115 \cdot 8\end{array}$ & $\begin{array}{r}757 \\
933 \\
1000 \\
1000 \\
1067\end{array}$ \\
\hline
\end{tabular}




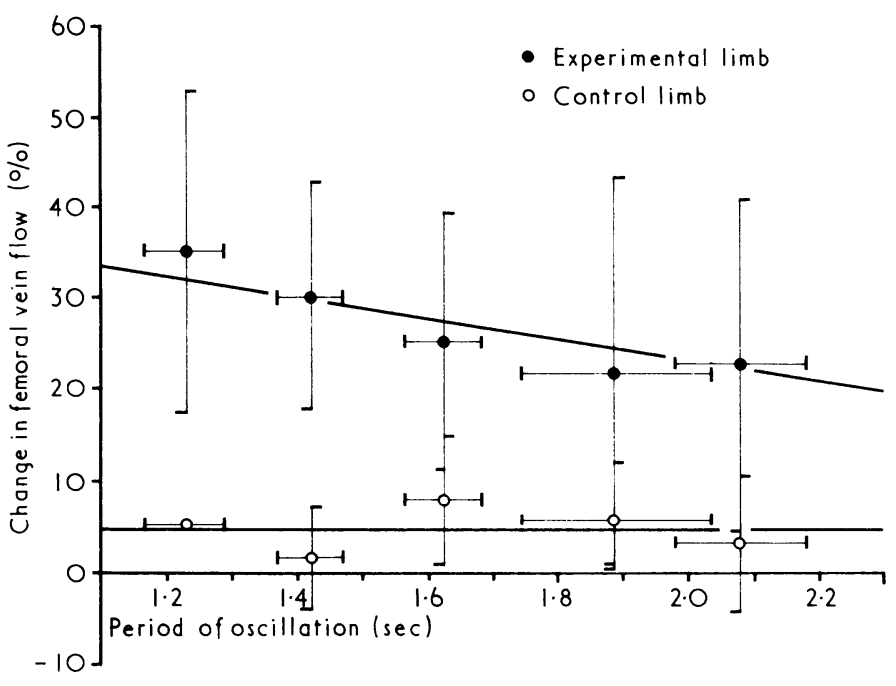

FIG. 3-Change in femoral vein flow in the experimental (flexed) and control (unflexed) limbs as a function of the oscillation period.

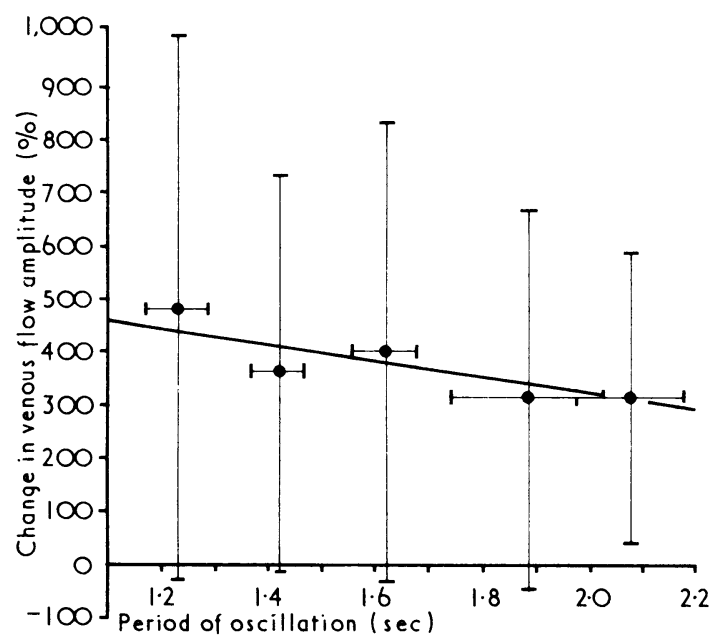

FIG. 4-Change in the amplitude of the pulsatile component of the venous flow wave as a function of the period of oscillation.

TABLE II-Changes in Femoral Vein Flow Produced by Passive Flexion of Foot. Flexion Rate Maintained at 50 per minute Throughout. Degree of Angulation of foot $(\theta)$ Tabulated Against Sustained Change in Control Limb Flow $\left(\Delta Q_{c}\right)$, of foot $(\theta)$ Tabulated Against Sustained Change in Control Limb Flow $\left(\Delta Q_{\mathrm{c}}\right)$,
Sustained Change in Experimental (Flexed) Limb Flow $\left(\Delta Q_{\mathrm{e}}\right)$, and Change in Sustained Change in Experimental (Flexed) Limb Flow $\left(\Delta Q_{\mathrm{e}}\right)$
Amplitude of Pulsatile Component of the Flow Wave $(\Delta A m p)$

\begin{tabular}{|c|c|c|c|c|c|}
\hline Subject & & $\theta=20^{\circ}$ & $\underset{\theta=30^{\circ}}{\text { Angulatio }}$ & $\begin{array}{l}f \text { foot } \\
\theta=40^{\circ}\end{array}$ & $\theta=50^{\circ}$ \\
\hline 6 & $\begin{cases}\Delta Q_{\mathrm{c}} & (\%) \\
\Delta Q_{\mathrm{e}} & (\%) \\
\Delta \mathrm{Amp} & (\%)\end{cases}$ & $\begin{array}{r}0 \cdot 0 \\
44 \cdot 0 \\
167\end{array}$ & $\begin{array}{r}0 \cdot 0 \\
39 \cdot 5 \\
180\end{array}$ & $\begin{array}{r}0 \cdot 0 \\
36 \cdot 1 \\
270\end{array}$ & $\begin{array}{r}2 \cdot 1 \\
37 \cdot 7 \\
350\end{array}$ \\
\hline 7 & $\begin{cases}\Delta Q_{\mathrm{c}} & (\%) \\
\Delta Q_{\mathrm{e}} & (\%) \\
\Delta \mathrm{Amp} & (\%)\end{cases}$ & $\begin{array}{c}\overline{9 \cdot 6} \\
150\end{array}$ & 200 & $\begin{array}{l}3 \overline{30 \cdot 0} \\
250\end{array}$ & $3 \overline{35 \cdot 4}$ \\
\hline 8 & $\begin{cases}\Delta Q_{\mathrm{c}} & (\%) \\
\Delta Q_{\mathrm{e}} & (\%) \\
\Delta \mathrm{Amp} & (\%)\end{cases}$ & $\begin{array}{c}4 \cdot 3 \\
15 \cdot 4 \\
600\end{array}$ & $\begin{array}{l}3 \cdot 3 \\
833\end{array}$ & $\begin{array}{c}0 \cdot 8 \\
31 \cdot 6 \\
1033\end{array}$ & $\begin{array}{l}-4 \cdot 9 \\
35 \cdot 7 \\
967\end{array}$ \\
\hline
\end{tabular}

Passive Flexion of Fixed Rate and Varying Amplitude.-The results of this part of the investigation are shown in Table II. The changes in control $\left(\Delta \mathbf{Q}_{\mathrm{c}}\right)$ and flexed $\left(\Delta \mathbf{Q}_{\mathrm{e}}\right)$ limb flows are tabulated against the four flexion amplitudes. Also given is the change produced in the amplitude of the pulsatile component of the flow wave. In Subject 7 no control readings were possible because of probe failure. Fig. 5 shows a curve plotted from the results in Table II. The net change in femoral vein flow in the flexed leg $\left(\Delta Q_{e}-\Delta Q_{c}\right)$ is plotted as a function of the angulation index $\theta$ (see Fig. 2). The vertical bars represent \pm 1 S.D. about the mean value obtained from the three subjects. The results for the change in pulsatility ( $\Delta \mathrm{Amp})$, though not plotted, show a similar trend.

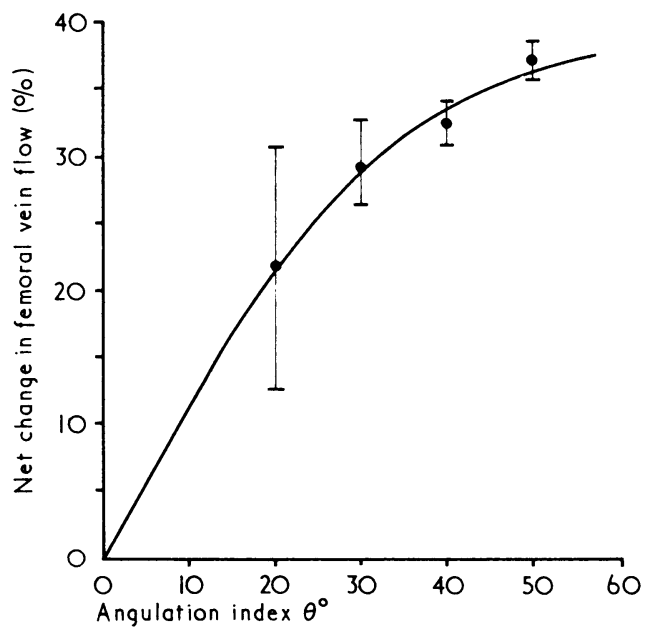

FIG. 5-Net change in flow in the flexed limb as a function of the angulation of the foot.

TABLE III-Changes in Femoral Vein Flow Produced by Sustained Passive Flexion. Flexion Rate Maintained at 50 per minute Throughout, with a Flexion Angle of $\pm 15^{\circ}$ About the Vertical $\left(\theta=30^{\circ}\right)$. Sustained Change in Control Limb Flow $\left(\Delta Q_{\mathrm{C}}\right)$ and Sustained Change in Experimental (Flexed) Limb Flow $\left(\Delta Q_{\mathrm{e}}\right)$ are Tabulated Against the Duration of Flexion

\begin{tabular}{|c|c|c|c|c|c|c|}
\hline \multirow{2}{*}{$\begin{array}{c}\text { Duration of } \\
\text { Flexion } \\
\text { (min) }\end{array}$} & \multicolumn{2}{|c|}{ Subject 9} & \multicolumn{2}{|c|}{ Subject 10} & \multicolumn{2}{|c|}{ Subject 11} \\
\hline & $\underset{(\%)}{\Delta Q_{e}}$ & $\frac{\Delta Q_{c}}{(\%)}$ & $\underset{(\%)}{\Delta Q_{e}}$ & $\frac{\Delta Q_{c}}{(\%)}$ & $\underset{(\%)}{\Delta Q_{e}}$ & $\underset{(\%)}{\Delta Q_{c}}$ \\
\hline $\begin{array}{r}5 \\
10 \\
15 \\
20 \\
25 \\
30\end{array}$ & $\begin{array}{l}23 \cdot 4 \\
26 \cdot 6 \\
29 \cdot 8 \\
31 \cdot 9 \\
34 \cdot 0 \\
36 \cdot 2\end{array}$ & $\begin{array}{r}-9.7 \\
-8.1 \\
-1.6 \\
1.6 \\
6.4 \\
9.7\end{array}$ & $\begin{array}{l}12.3 \\
14.5 \\
15 \cdot 0 \\
16 \cdot 0 \\
12.5 \\
11.2\end{array}$ & $\begin{array}{l}1 \cdot 7 \\
0 \cdot 0 \\
2 \cdot 8 \\
2 \cdot 9 \\
4 \cdot 8 \\
3 \cdot 4\end{array}$ & $\begin{array}{l}51 \cdot 1 \\
65 \cdot 9 \\
69 \cdot 3 \\
72 \cdot 7 \\
60 \cdot 2 \\
52 \cdot 2\end{array}$ & $\begin{array}{r}9 \cdot 2 \\
7 \cdot 0 \\
12.0 \\
9.9 \\
-3.5 \\
-9.9\end{array}$ \\
\hline
\end{tabular}

Sustained Passive Flexion of Fixed Rate and Amplitude.The results of the third part of the investigations are shown in Table III. The sustained changes in flow (referred to the resting flows before flexion) are shown at five-minute intervals during 30 minutes of continuous flexion. Changes in control limb flow $\left(\Delta \mathrm{Q}_{\mathrm{c}}\right)$ and flexed limb flow $\left(\Delta \mathrm{Q}_{\mathrm{e}}\right)$ are given. The results, though not plotted graphically, show that the increase in flow produced by passive flexion is maintained for at least $\mathbf{3 0}$ minutes without appreciable diminution.

Relationship between Resting Flow and Change Produced by Flexion.-In order to evaluate the relationship between the flow in the experimental limb and the increases produced in this by passive flexion, the flows from which Table I was derived were used. For each setting of the foot-mover speed on each of the five subjects, the net percentage change in flow referred to the control $\operatorname{limb}\left(\Delta Q_{e}-\Delta Q_{c}\right)$ was tabulated against the rest flow in the experimental (flexed) limb before flexion. However, the change in flow depends on the oscillation period, as shown in Fig. 3. In order to eliminate this effect the flows were normalized, quite arbitrarily, to an oscillation period of $T=1 \mathrm{sec}$ and then plotted as a scatter diagram, which is shown in Fig. 6, the net change in flow referred to the control limb being plotted as a function of the resting femoral vein flow 


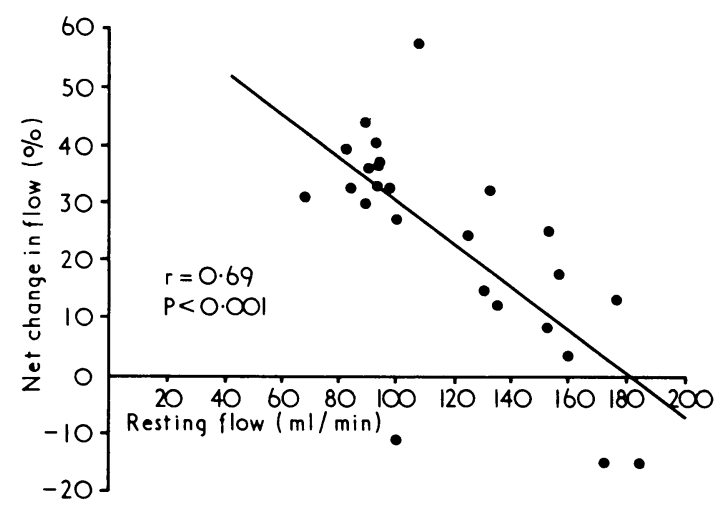

FIG. 6-Net change in flow in the flexed limb as a function of the resting flow before flexion. Computed for a flexion rate of 60 per minute $(T=1 \mathrm{sec})$.

before flexion. The resulting population indicates a highly significant correlation between the two measurements $(r=0.69$, $P<0.001)$. The regression line indicates that for resting femoral vein flows below $180 \mathrm{ml} / \mathrm{min}$ the lower the flow, the greater the increase produced by passive flexion.

\section{Discussion}

That the original site of postoperative deep vein thrombosis is most commonly the veins of the calf, especially the soleal sinuses (Gibbs, 1957; Roberts, 1963; Cotton and Clark, 1965) led to the belief that the thrombus spreads from the soleal sinuses in the direction of the venous flow (Gibbs, 1957; Roberts, 1963). Furthermore, radiographic studies have shown that in the resting recumbent state the soleus intramuscular venous system is functionally isolated (Clark, Cotton and Zarek, 1965), and Clark and Cotton (1968) later showed that induction of general anaesthesia by thiopentone sodium reduces popliteal and external iliac vein flow in patients by $50 \%$ or more. A reduction which is maintained throughout the period of general anaesthesia.

This work has led to the belief that stasis and/or the associated diminution of both the mean flow and its pulsatility may be an initiating factor for the subsequent deep vein thrombosis. Accordingly it was suggested that exercise of the calf muscles was necessary to eliminate the stasis in the calf veins. Furthermore, the observations that most deep vein thrombi are initiated per-operatively (Flanc et al., 1968; Negus et al., 1968) indicates that this exercise should begin immediately following induction of general anaesthesia and be continued throughout the entire operation.

Until now, electrical stimulation of the calf muscles has been the only technique by which such per-operative exercise can be satisfactorily achieved. The resulting rhythmical contraction of the calf muscles allows adequate filling and emptying of the soleal sinuses, whereas the application of static external pressures, though augmenting the flow in the deep veins (Spiro et al., 1970), does not result in any filling of the soleal venous system (Clark et al., 1965).

Electrical stimulation of the calf, however, requires the application of some four electrodes, and its effect varies with the anaesthetic condition of the patient (Browse and Negus, 1970).
Furthermore, skin erythema and blistering can occur. A motorized foot mover, on the other hand, provides a safe practical method of obtaining rhythmical passive exercise of the calf muscles. It can be used whenever or wherever it is required on most patients without disturbance, and is equally suitable for use during both the per-operative and postoperative periods.

It has been shown that per-operative flexion of the feet can increase the mean femoral vein flow by $35 \%$, increase the peak femoral vein flow by over $55 \%$, and increase the pulsatility of the flow fourfold. Furthermore, these increases vary with the rate of flexion, a fact which may in part explain why some have been more successful than others in finding calf stimulation an effective prophylactic against postoperative deep vein thrombosis (Roberts, Sabri, Pietroni, and Cotton, 1970).

The effects of passive flexion on changes in the venous flow varied considerably from subject to subject, possibly because of the varying degree of venous valvular incompetence. Furthermore, the poor efficiency of the calf muscle pump in varicose vein patients (Roberts, Sabri, and Cotton, 1971) suggests that the effects of passive flexion will be even greater in most patients. Despite this variation it is evident that the effects of sustained passive flexion can be maintained, without appreciable diminution, for at least 30 minutes, the increase in flow being proportional to the rate and amplitude of the flexion and reaching a maximum value when $0=57^{\circ}$ at a rate of 50 per minute.

In conclusion, it is generally agreed that successful prophylaxis against postoperative deep vein thrombosis must aim at reducing the stasis of venous blood in the calf during and immediately after operation. Until now, no single method has been able to satisfy this dual need.

The foot mover that we have used in this investigation is simple and requires no attention during use. It can be applied both at and after operation with equal facility. We believe, therefore, that it will prove to be a simpler and more effective prophylactic against postoperative deep vein thrombosis than any available hitherto.

We are indebted to the Wates Foundation for their generosity in financing this investigation.

\section{References}

Browse, N. L., and Negus, D. (1970). British Medical fournal, 3, 615.

Clark, C., Cotton, L. T., and Zarek, J. M. (1965). In Biomechanics and Related Bioengineering Topics, ed. R. M. Kenedi. London, Pergamon.

Cotton, L. T., and Clark, C. (1965). Annals of the Royal College of Surgeons of England, 36, 214.

Cotton, L. T., Fowler, J. F., and Miles, J. M. (1959). British fournal of Radiology, 32, 645 .

De Jode, L. R., Khurshid, M., and Walther, W. W. (1970). British Medical Fournal, 4, 56.

Doran, F. S. A., Drury, M., and Sivyer, A. (1964). British fournal of Surgery, $51,486$.

Doran, F. S. A., and White, H. M. (1967). British fournal of Surgery, 54, 686.

Flanc, C., Kakkar, V. V., and Clarke, M. B. (1968). British fournal of Surgery, 55, 742 .

Gibbs, N. M. (1957). British fournal of Surgery, 45, 209.

Moloney, G. E., Morrell, M. T., and Fell, R. H. (1970). British Medical fournal, 4, 244 .

Negus, D., Pinto, D. J., LeQuesne, L. P., Brown, N., and Chapman, M. (1968). British Fournal of Surgery, 55, 835

Roberts, G. H. (1963). Scottish Medical fournal, 8, 11

Roberts, V. C., Sabri, S., and Cotton, L. T. (1971). In press.

Roberts, V. C., Sabri, S., Pietroni, M. C., and Cotton, L. T. (1970). British Medical fournal, $4,556$.

Sabri, S., Roberts, V. C., and Cotton, L. T. (1971). British Medical fournal, 3,82 .

Spiro, M., Roberts, V. C., and Richards, J. B. (1970). British Medical Fournal, 1, 719.

Wright, H. P., and Osborn, S. B. (1952). British Heart fournal, 14, 325.

Wright, H. P., Osborn, S. B., and Edmonds, D. G. (1951). Lancet, 1, 22. 